\title{
Torque and drag modelling for Redhill South-1 in the Northern Perth Basin, Australia
}

\author{
S. Smith \& V. Rasouli \\ Department of Petroleum Engineering, Curtin University, Australia
}

\begin{abstract}
Drilling deviated and horizontal wells is commonly used in the oil and gas industry for different purposes. Particularly in unconventional reservoirs such as gas shales or tight formations, horizontal wellbores provide a larger exposure to the formation, which enhances the production from such tight formations. The increase in torque and drag forces downhole in deviated borehole trajectories is one of the technical challenges that needs to be carefully studied during the design phase. There have been a number of different approaches to the way that torque and drag has been modelled in the industry. These include the soft string and stiff string approach and accounting for the effects of viscous fluid flow. The soft string model treats the drill string as a cable and assumes that it lies against the low side of the wellbore, meaning that the stiffness of the drill string is not accounted for. On the other hand, stiff string models take into account the stiffness and bending moment in the drill string and the radial clearance in the wellbore. Fluid flow during drilling results in the loss of the normal component of fluid pressure on the drill string as the flowing condition becomes dynamic. There is also an additional tangential component caused by viscous drag on the drill string due to the fluid flow.

In this paper we will present the findings of a study aimed at determining the most appropriate type of torque and drag modelling approach that should be applied for Norwest Energy's Redhill South-1 well and future wells of similar nature. Redhill South-1 was directionally drilled to test the gas potential of the Permian sands in a fault dependent structural closure. Both soft and stiff string approaches will be studied. The necessity to account for viscous drag effects will also be analysed.
\end{abstract}

Keywords: torque and drag, soft string, stiff string, viscous fluid flow. 


\section{Introduction}

When a drilled borehole deviates from the true vertical direction, the contact between the drill string and drill hole generates frictional forces and normal forces. These frictional and normal forces oppose the direction of drill string motion, arising to the effects of torque and drag. Drag is defined as the additional force required for moving the pipe up or down in the borehole as a result of the generated frictional forces and contact loads, while torque is the additional moment force required to rotate the pipe [1].

Frictional and normal forces are a function of the drilling parameters and surfaces encountered. Drilling parameters that affect the coefficient of friction and normal forces include, but are not limited to, drilling mud properties, well path design, hole section surfaces encountered and tubular design. Surfaces encountered are usually simplified to contact between tubulars and casing in cased hole and contact between tubulars and formations in open hole. Typical friction coefficients for cased hole and open hole while drilling with water-based mud are 0.25 and 0.35 respectively [2].

It is important to understand that the effects of torque and drag are also influenced by the mode that drilling is happening or the operation that is being conducted. With regards to the motion of the drill string, there are two drilling modes, sliding and rotating. Sliding is where the drill string is displaced axially up and down the drill hole, while rotating is where the drill pipe is rotated about a point in the drill hole. Sliding of the drill string greatly contributes to drag forces but minimal to torque, while the opposite is true for rotating of the drill string [3]. Other drilling operations include tripping in and out of the well.

In order to effectively model torque and drag for drilling a well, Johancsik et al. [4] developed the soft string model, where the equations established are presented in section 2 . The soft string model assumes that the entire drill string lies against the low side of the wellbore meaning that the stiffness of the drill string is not accounted for. For modelling purposes, the drill string is represented by a cable divided up into small elements that only carry axial loads and torque, while the contact forces are supported by the wellbore [5].

In addition to soft string modelling, stiff string models have been developed as an attempt to model a more realistic situation downhole. McCormack et al. [5] describe that stiff string models endeavour to do this by taking into account the stiffness and bending moment in the tubular and radial clearance in the wellbore that results. However, they also suggest that even though stiff string models incorporate more variables, it is not necessarily more accurate than a soft string model. The decision to choose between a soft string or stiff string model is dependent on the well situation. Stiff string models are more beneficial for wells that have high tortuous trajectories, high dogleg severity or stiff tubulars [5].

The effects of fluid flow on torque and drag modelling is varied and not taken into account by all models. Fluid flow during drilling results in the loss of the normal component of fluid pressure on the drill string as the static condition is broken. There is also an additional tangential component caused by viscous drag 
on the drill string due to the fluid flow [6]. The additional force due to viscous drag is calculated as follows [7]:

$$
\Delta F=\frac{\Delta P \pi\left(D_{h}^{2}-D_{p}^{2}\right) D_{p}}{4\left(D_{h}-D_{p}\right)}
$$

where $F$ is the force $(N), \Delta P$ is the annular pressure loss based on rheological model selected $(\mathrm{Pa}), D_{h}$ is the diameter of the hole $(m)$ and $D_{p}$ is the diameter of the pipe $(m)$. The determination of annular pressure loss for different rheological models has been already reported in Applied Drilling Engineering [8]. There is no direct calculation of viscous drag due to pipe rotation.

The additional torque on the pipe due to viscous drag is calculated as follows [7]:

$$
\Delta T=\tau_{t} 2 \pi L\left(\frac{D_{p}}{2}\right)^{2},
$$

where $T$ is the torque (N.m), $\tau_{\mathrm{t}}$ is the shear stress based on the rheological model selected $(\mathrm{Pa})$ and $L$ is the length of the pipe $(\mathrm{m})$. Further details about determination of shear stress for different rheological models can be found in Applied Drilling Engineering [8].

In this paper the calculations of torque and drag are presented for the Redhill South-1 well in northern Perth Basin.

\section{Calculating torque and drag}

The first notable analysis of torque and drag was performed by Johancsik et al. [4], who established well friction equations in deviated wellbores. They assumed both torque and drag are caused entirely by sliding friction forces that results from contact between the drill string and the wellbore. They defined the sliding friction force to be a function of the normal contact force and the coefficient of friction between the contact surfaces based on Coulomb's friction model. The normal force is given by:

$$
F_{n}=\sqrt{\left(F_{t} \Delta \alpha \sin \theta\right)^{2}+\left(F_{t} \Delta \theta+w \sin \theta\right)^{2}} .
$$

In this equation $F_{n}$ is the normal force $(N), F_{t}$ is the tensile force $(N), \alpha$ is the inclination angle (deg), $\theta$ is the dogleg angle (deg) and $w$ is the weight of pipe $(N)$. This is then used to derive the equation for tension increments as:

$$
\Delta F_{t}=w \cos \theta \pm \mu F_{n}
$$

where $\mu$ is the coefficient of friction, ' + ' is used in upward movements and '-' is used in downward movements of the drill string. Also, the torsion increment is calculated as:

$$
\Delta M=\mu F_{n} r
$$

where $M$ is the torque (N.m), and $r$ is the radius of pipe $(m)$. 
Later Sheppard et al. [9] put the Johancsik's et al. model [4] into standard differential form and also took the mud pressure into account that acts upward when the drill string is running into the hole. This means he modelled effective tension instead of true tension and defined the effective tension as the sum of the true tension and mud pressure.

Since then, there have been numerous applications and developments of these two works. More recently, Aadnoy and Djurhuus [10] undertook a mathematical study analysing published friction models to provide a generalized friction model consisting of only two equations, one for rotating friction (torque) and one for pulling friction (drag) that is valid for all well geometries such as vertical sections, build up sections, drop off sections and straight sections. However, these solutions were still limited to horizontal and vertical planes. Aadnoy et al. [11] were able to extend these solutions to a 3D geometry.

\section{Redhill South-1 well}

Redhill South-1 is located in northern Perth Basin, in the central east area of Permit TP/15. Redhill South-1 was directionally drilled to test the gas potential of the Permian sands in a fault dependent structural closure [12]. A 13\% " conductor was originally set at $90 \mathrm{mMD}$ prior to the drilling rigs arrival on site. Spudding commenced on February 282011 with a 121/2" surface hole that was directionally drilled to $1309 \mathrm{mMD}$ and cased with a $95 / 8$ " casing. An $81 / 2$ " hole was then vertically drilled to a TD of $1896 \mathrm{mMD}$, which was reached on March 182011. Bottom hole location at TD was $322 \mathrm{~m}$ west $\left(260^{\circ}\right)$ of the surface location [12].

Redhill South-1 is a build and drop type wellbore trajectory as can be seen in the $3 \mathrm{D}$ model in Figure 1. The well is vertical until the KOP at $185.51 \mathrm{mMD}$ with

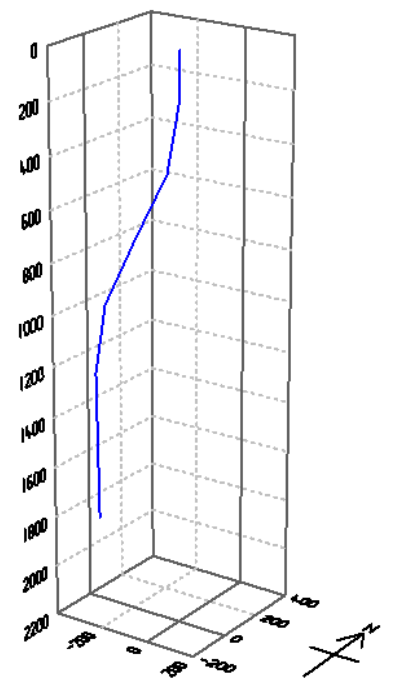

Figure 1: $\quad 3 \mathrm{D}$ well trajectory of Redhill South-1. 
a build rate of $2.15^{\circ} / 100 \mathrm{ft}$, as is shown in Figure 2 . At approximately $457 \mathrm{mMD}$, the build rate drops to $1.24^{\circ} / 100 \mathrm{ft}$ to an end of build at approximately $750 \mathrm{mMD}$ where the trajectory starts to drop at a drop off rate of $1.55^{\circ} / 100 \mathrm{ft}$. The maximum inclination reached at this point is approximately $31^{\circ}$. The well trajectory reaches a maximum drop off of $1.77^{\circ} / 100 \mathrm{ft}$ until approximately $1210 \mathrm{mMD}$ where the drop off rate starts to decrease. At $1309 \mathrm{mMD}$ the well is drilled vertical to TD at $1896 \mathrm{mMD}$ (1835mTVD).

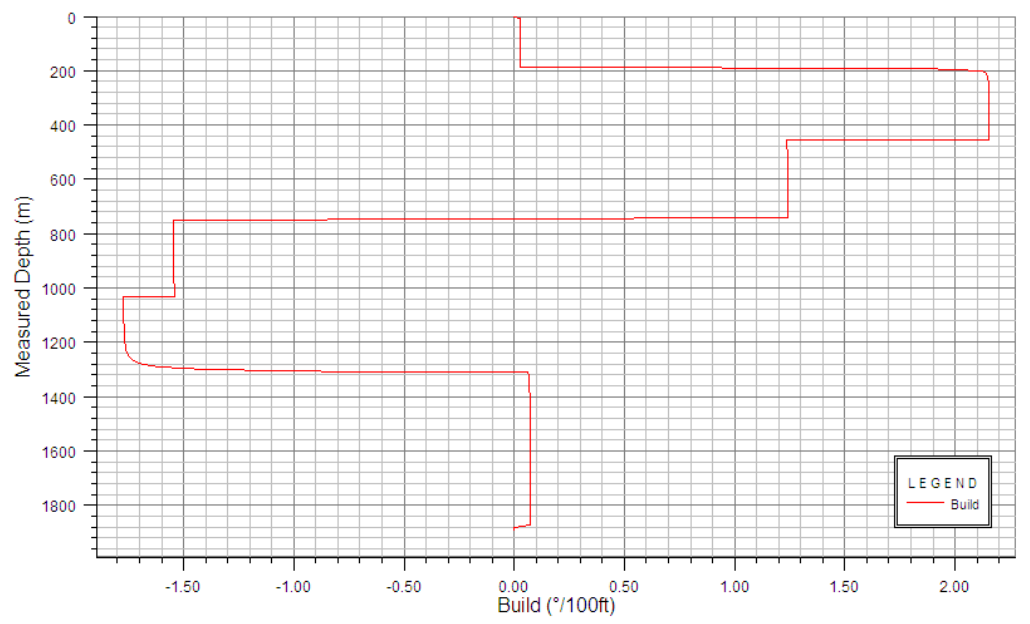

Figure 2: Build angle over well trajectory.

Table 1 shows the modelled hole sections for Redhill South-1. As the $81 / 2$ " hole was drilled with water based mud with a density of approximately $9.67 \mathrm{ppg}$ (1.16SG), friction factors of 0.25 for cased hole and 0.35 for open hole were chosen to be modelled as suggested by McCormack et al. [2].

Table 1: $\quad$ Modelled hole sections for Redhill South-1.

\begin{tabular}{|l|c|c|c|c|}
\hline Section Type & MD (m) & ID (in) & $\begin{array}{l}\text { Effective Hole } \\
\text { Diameter (in) }\end{array}$ & $\begin{array}{l}\text { Friction } \\
\text { Factor }\end{array}$ \\
\hline $\begin{array}{l}13 \text { 3/8”, 68ppf, N-80 } \\
\text { Casing }\end{array}$ & 90.00 & 12.415 & 17.500 & 0.25 \\
\hline $\begin{array}{l}9 / 8 ”, 47 p p f, ~ N-80 \\
\text { Casing }\end{array}$ & 1309.00 & 8.681 & 12.347 & 0.25 \\
\hline Open Hole & 1896.00 & 8.500 & 8.500 & 0.35 \\
\hline
\end{tabular}

\section{Modelled drill string}

Table 2 demonstrates the modelled drill string for drilling Redhill South-1 to TD. The modelled drill string components were chosen from the Wellplan catalogue 
using the Drilling and Formation Evaluation Program for Redhill South-01 Exploration Well [13] description of $81 \frac{1}{2}$ " bottom hole assembly as a guide. It should be noted that an Andadrift tool (3.5m in length) that should exist between the stabilizer and non-magnetic drill collar could not be included, as it did not exist in the catalogue. This means an additional $3.5 \mathrm{~m}$ of $4 \frac{1}{2} 2,16.6 \mathrm{ppf}$ drill pipe was added to the top of the drill string.

Table 2: $\quad$ Modelled drill string for Redhill South-1.

\begin{tabular}{|l|c|c|c|c|}
\hline $\begin{array}{c}\text { Drill String } \\
\text { Component }\end{array}$ & $\begin{array}{c}\text { MD } \\
\text { (m) }\end{array}$ & $\begin{array}{c}\text { OD } \\
\text { (in) }\end{array}$ & $\begin{array}{c}\text { ID } \\
\text { (in) }\end{array}$ & $\begin{array}{c}\text { Weight (including } \\
\text { connections) (ppf) }\end{array}$ \\
\hline Drill Pipe & 1309.24 & 4.50 & 3.826 & 19.09 \\
\hline Drill Pipe & 1695.51 & 4.50 & 3.500 & 25.83 \\
\hline $\begin{array}{l}\text { Heavy Wall Drill } \\
\text { Pipe }\end{array}$ & 1751.31 & 6.50 & 5.901 & 41.46 \\
\hline Drill Collar & 1788.51 & 6.50 & 2.813 & 91.76 \\
\hline Jar & 1798.01 & 6.50 & 2.750 & 126.32 \\
\hline Drill Collar & 1872.41 & 6.50 & 2.813 & 91.76 \\
\hline X-Over & 1873.32 & 6.72 & 2.760 & 100.63 \\
\hline Stabilizer & 1875.12 & 6.75 & 2.813 & 83.27 \\
\hline $\begin{array}{l}\text { Non-Magnetic } \\
\text { Drill Collar }\end{array}$ & 1884.42 & 6.75 & 2.813 & 99.59 \\
\hline Stabilizer & 1886.22 & 6.75 & 2.813 & 83.27 \\
\hline Mud Motor & 1895.72 & 6.75 & 3.000 & 63.88 \\
\hline PDC Bit & 1896.00 & 8.50 & - & 75.00 \\
\hline
\end{tabular}

The drilling operations that were modelled include:

- Rotating on bottom with 25 kips WOB and 10,000 ft-lbf torque at bit

- Rotating off bottom

- Slide drilling with 25 kips WOB and 10,000t-lbf torque at bit

- Tripping out at $40 \mathrm{ft} / \mathrm{min}$ and $0 \mathrm{rpm}$

- Tripping in at $40 \mathrm{ft} / \mathrm{min}$ and $0 \mathrm{rpm}$

WOB and torque at bit values were chosen based on data from the Redhill South-1 Well Completion Report [9] that was described when drilling to TD. Tripping out and tripping in speeds and rpm's were chosen as arbitrary values for these operations. The drill string modelling, using Halliburton's Landmark WELLPLAN software [7], based on the soft and stiff approach and including the effect of drilling fluid will be presented in the following subsections.

\subsection{Soft string approach with no viscous fluid effects}

Accumulative torque and effective tension using a soft string approach with no viscous fluid effects have been plotted against MD and are shown in Figures 3 and 4 respectively. From the two figures we can see that the maximum forces are 


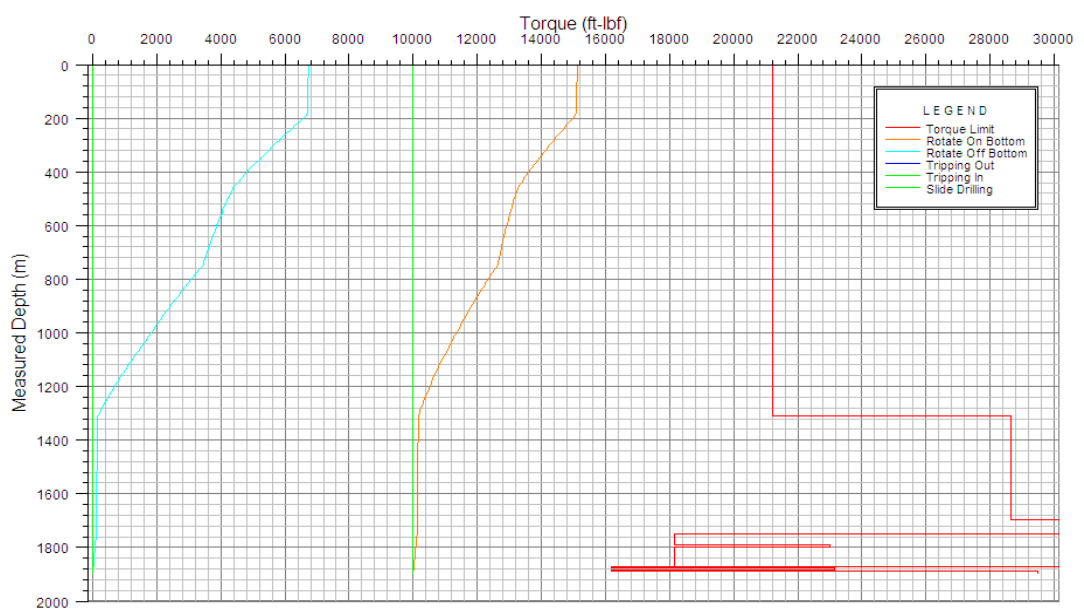

Figure 3: Torque plot calculated using soft string approach with no viscous fluid effects.

experienced at the top of the drill string as was suggested by Maehs et al. [14]. This is because these forces are an accumulation from bottom to top.

Figure 3 shows that torque starts to accumulate above $1300 \mathrm{mMD}$ for rotating on bottom and rotating off bottom, especially with a sharper increase between 200-400 mMD and 700-1300 mMD. Explanations for these trends can be found in Figure 5, which shows the side force per normalization length (30ft). From this plot it can be seen that an increase in side force is experienced between these depths. Comparing it to Figure 2, it can be seen that the increase in side forces between these depths can be attributed to the build and drop off rate. Between the depths of $200-400 \mathrm{mMD}$ there exists a build rate of $2.15^{\circ} / 100 \mathrm{ft}$, while a drop off rate of $1.55^{\circ} / 100 \mathrm{ft}$ exists between $700-1300 \mathrm{mMD}$. Between the depths of 400-700 mMD the build rate decreases to $1.24^{\circ} / 100 \mathrm{ft}$, explaining the lower degree of side forces, and hence a lower increase of torque forces. This suggests that the deviation contributes to the side force experienced and hence the greater degree of torque. Equation 5, which shows that an increase in the normal force will result in an increase in torque, can support these findings.

Figure 3 also shows that for tripping in and tripping out has zero torque. This is because the pipe rotation is zero. Using the equations developed by Aadnoy and Djurhuus [10] for torque, we see that when the pipe rotation is equal to zero, the friction angle ' $\psi$ ' equals zero, and hence zero torque. We can also see that the torque for slide drilling is constant at $10,000 \mathrm{ft}-\mathrm{lbf}$, which is equal to the bit torque. It does not increase above this value because there is also no pipe rotation.

In Figure 4, we can see that the effective tension forces for the different drilling operations accumulate at different rates. In Figure 5, the side forces increase in the following order; tripping out, rotate off bottom, tripping in, rotate on bottom and slide drilling. The differences in side forces for the various drilling operations can help explain the different rates that effective tension 


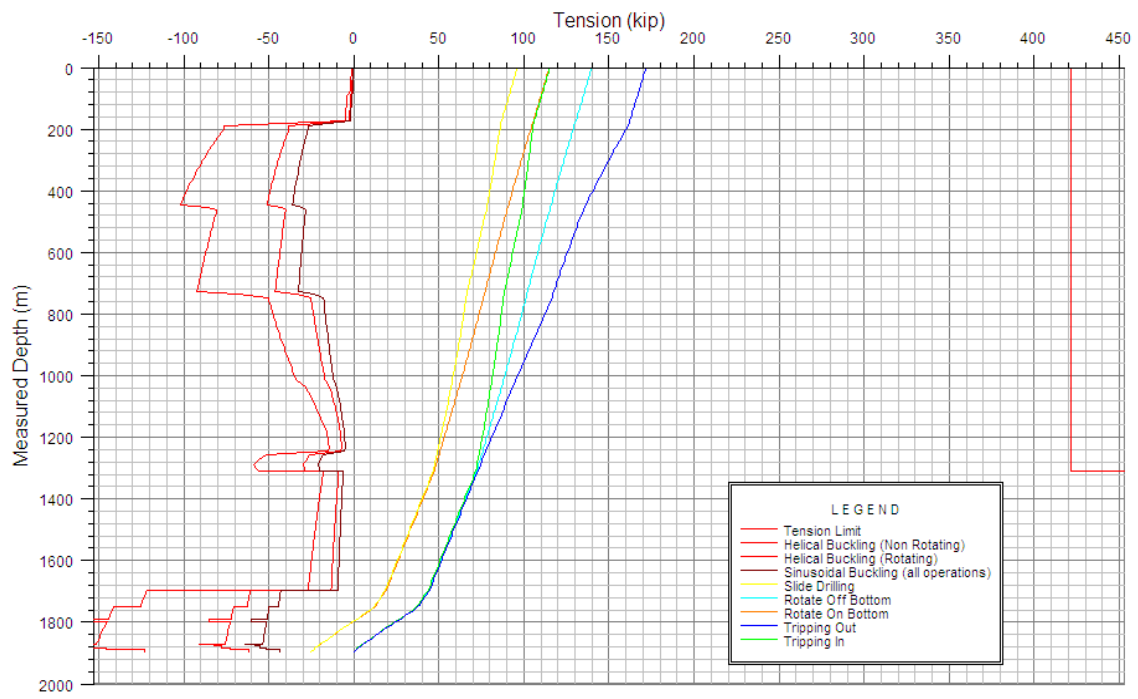

Figure 4: Effective tension plot calculated using soft string approach with no viscous effects.

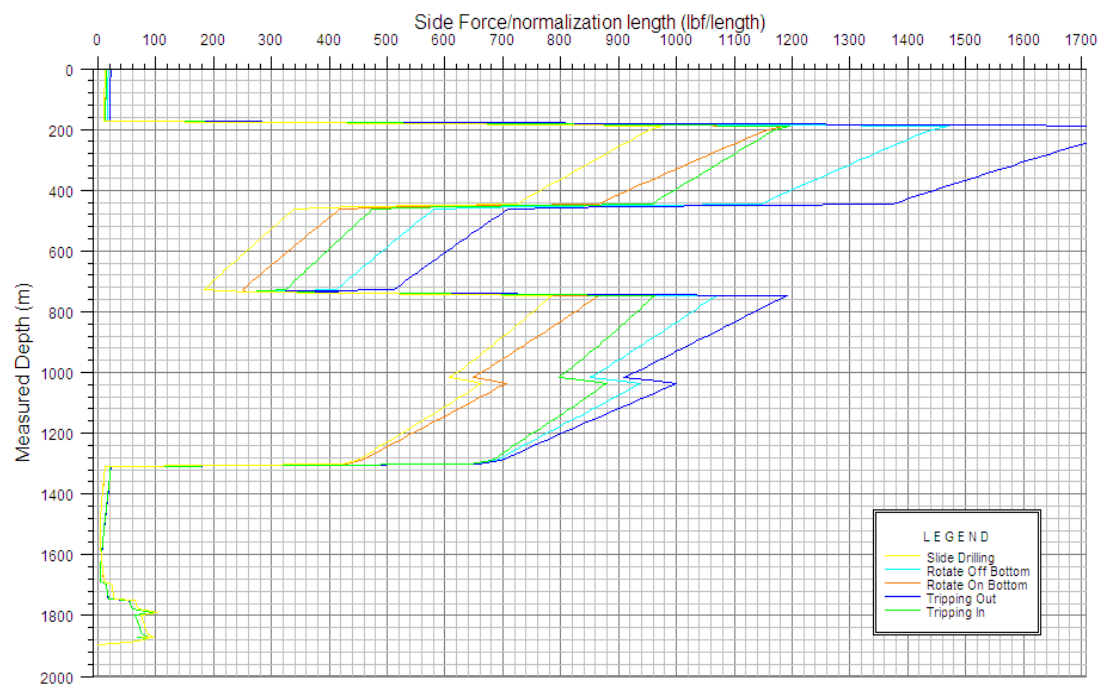

Figure 5: Plot of side force per normalized length calculated using soft string approach with no viscous fluid effects.

accumulates. Explanations for this can also be taken from Equation (4), where the normal force is added for upward movements of the drill string and subtracted for downward movements. 
From the two figures of torque and effective tension we can see that the modelled drill string is in no danger of failure due to buckling, twist off or snap off as the tracks do not intersect any of the failure limits.

\subsection{Stiff string approach with no viscous fluid effects}

Accumulative torque and effective tension using a stiff string approach with no viscous fluid effects have been plotted against MD and are shown in Figures 6 and 7 respectively. From the two figures, it can be seen that the trends for torque and effective tension remain unchanged when compared to the soft string approach with only minimal changes in downhole forces experienced. In addition, the drill string still remains in no danger of failure. Comparison between the two approaches showed the following results:

- The maximum torque decreased by $47.3 \mathrm{ft}-\mathrm{lbf}$ for rotating on bottom and increased by $110 \mathrm{ft}-\mathrm{lbf}$ for rotating off bottom. Maximum torque for slide drilling, tripping out and tripping in remained unchanged.

- Maximum effective tension decreased by $0.1 \mathrm{kips}$ for slide drilling, increased by $1.7 \mathrm{kips}$ for tripping out and decreased by 0.8 kips for tripping in. Maximum effective tension for rotating on bottom and rotating off bottom remained unchanged.

- Maximum drag increased by $1.4 \mathrm{kips}$ for tripping out and decreased by $0.8 \mathrm{kips}$ for tripping in. Slide drilling, rotating on bottom and rotating off bottom remained unchanged.

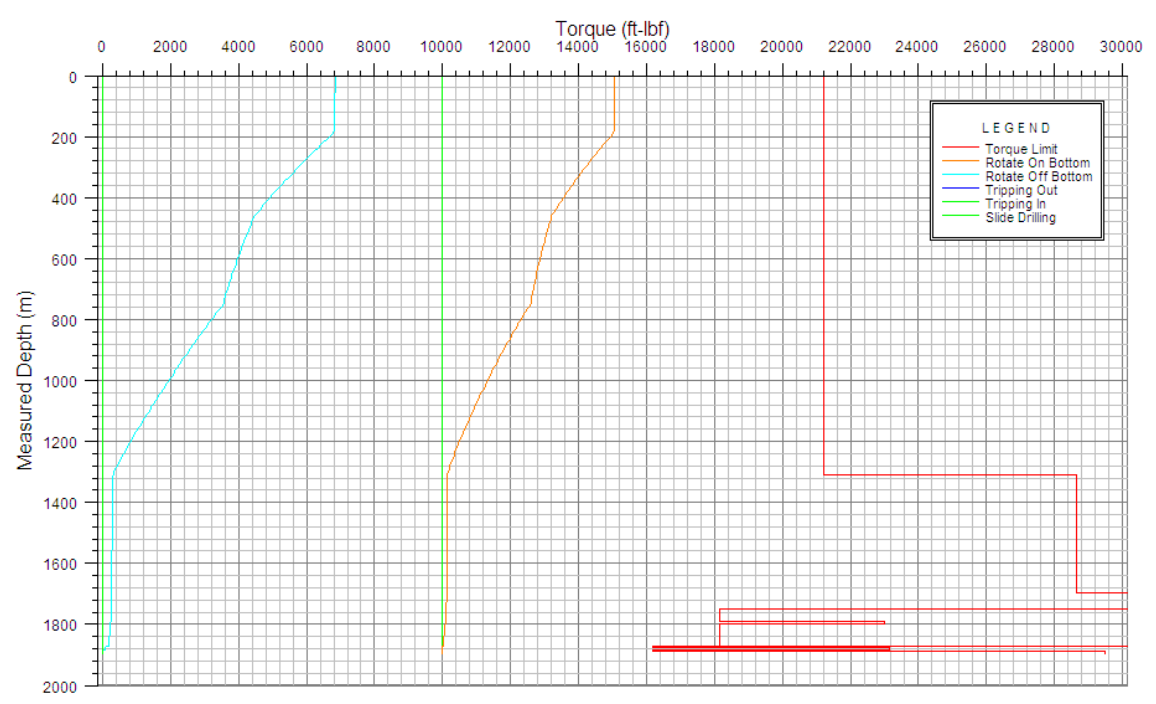

Figure 6: Torque plot calculated using stiff string approach with no viscous fluid effects. 


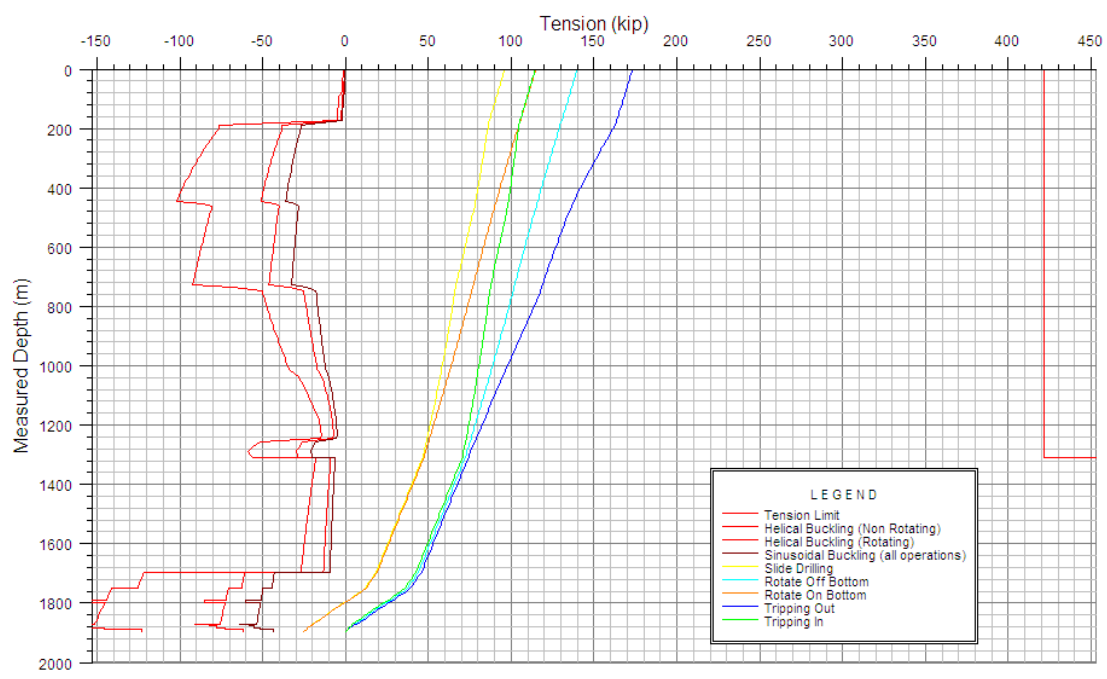

Figure 7: Effective tension plot calculated using stiff string approach with no viscous fluid effects.

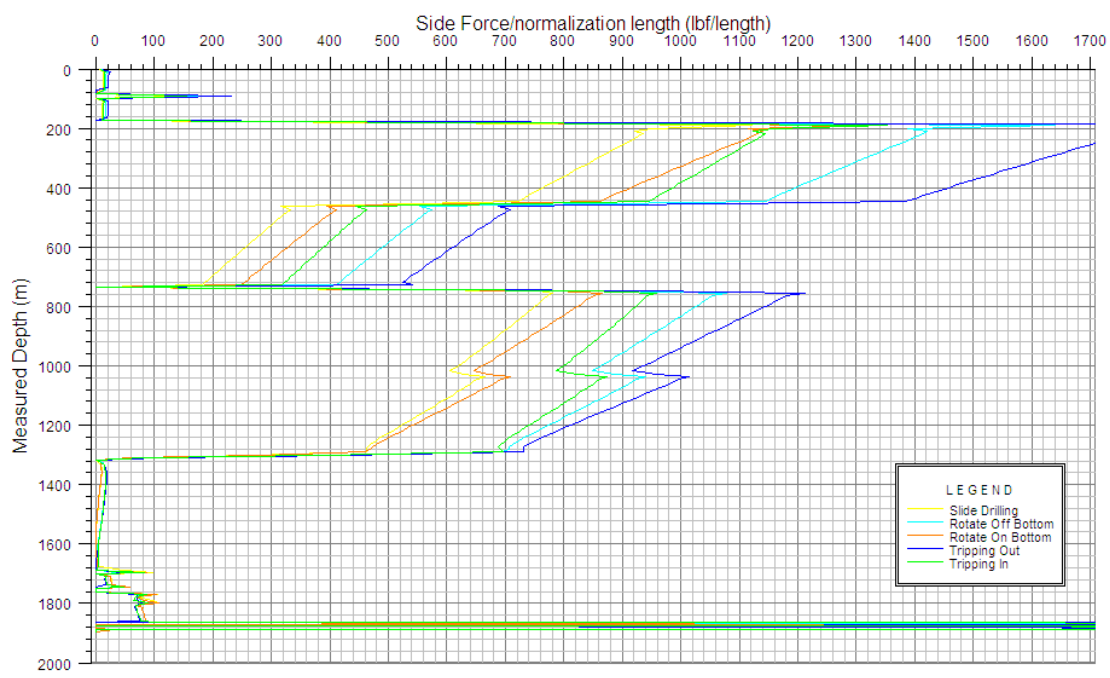

Figure 8: Plot of side force per normalized length calculated using stiff string approach with no viscous fluid effects.

These changes in forces experienced are a result of the change in side forces as shown in Figure 8. These changes in side forces can be attributed to the fact that stiffness in the drill string is accounted for and its position is no longer assumed to remain on the low side of the borehole wall. 


\subsection{Modelling with viscous fluid effects}

The maximum forces experienced in the well for both the soft string and stiff string approach when taking into account viscous fluid effects showed the following results:

- Maximum torque increased by $339.2 \mathrm{ft}-\mathrm{lbf}$ for rotating on bottom and rotating off bottom. Slide drilling, tripping in and tripping out remained unchanged.

- Maximum Effective tension increased by 3kips for tripping out and decreased by 2.1 kips for tripping in. Rotating on bottom, rotating off bottom and slide drilling remained unchanged.

- Maximum drag increased by 2.9kips for tripping out and decreased by 2.1kips for tripping in. Rotating on bottom, rotating off bottom and slide drilling remained unchanged.

- Viscous fluid effects did not vary with the type of modelling approach, soft string or stiff string.

Once again, accounting for viscous fluid effects shows a negligible difference in torque and drag and did not change the overall trend of torque and effective tension plots.

\section{Conclusions}

Modelling of torque and drag for Redhill South-1 showed a direct correlation between the accumulation of downhole forces and well trajectory. As the build up rate or drop off rate increased, torque and effective tension accumulated at a higher rate. Modelling also showed that no section of the drill string was in danger of failure.

Comparing the results produced for both modelling approaches, we can conclude that both soft string and stiff string approaches provide adequate solutions for torque and drag modelling of Redhill South-1. However, it is the authors' recommendation to use the stiff string approach when modelling torque and drag for wells of similar nature as it takes into account the stiffness and bending moment in the drill string providing for a more realistic situation. Accounting for viscous fluid effects showed minimal impact on the modelling of torque and drag in the well. However, given that the maximum forces experienced downhole all increased (with the exception of maximum effective tension and drag for tripping in) due to viscous fluid effects, it would be safest practice for these forces to be accounted for.

\section{Acknowledgements}

The authors would like to acknowledge Norwest Energy for providing access to all the well data required to complete this study. Additionally, allowing for this paper to be published. Lastly, the authors would like to thank AGR for providing access to their Landmark Wellplan software to be able to perform the modelling. 


\section{References}

[1] Mirhaj, S.A, M. Fazaelizadeh, E. Kaarstad, B.S Aadnoy. 2010. "New Aspects of Torque-and-Drag Modeling in Extended-Reach Wells." Paper was prepared for presentation at 2010 SPE Annual Technical Conference and Exhibition, Florence, Italy, September 19-22. doi: 10.2118/135719MS.

[2] McCormack, J.E, C.D Evans, J. Le, T. Chiu. 2011. "The Practice and Evolution of Torque and Drag Reduction: Theory and Field Results." Paper was prepared for presentation at 2012 International Petroleum Technology Conference, Bangkok, Thailand, February 7-9. doi: 10.2523/14863-MS.

[3] Mitchell, B. 1974. Oilwell Drilling Engineering Handbook. Richardson: Society of Petroleum Engineers.

[4] Johancsik, C.B, D.B Frieson, R. Dawson. 1984. "Torque and Drag in Directional Wells - Prediction and Measurement." Journal of Petroluem Technology 36 (6): 987-992. doi: 10.2118/11380-PA.

[5] McCormack, J.E, M. Frilot, T. Chiu. 2011. "Torque and Drag Software Model Comparison: Impact on Application and Calibration of Field Data." Paper was prepared for presentation at 2011 Brazil Offshore Confreernce and Exhibition, Macae, Brazil, June 14-17. doi: 10.2118/143623-MS.

[6] Mason, C.J, D.C.K Chen. 2007. "Step Changes Needed To Modernize T\&D Software." Paper was prepared for presentation at 2007 IADC/SPE Drilling Conference, Amsterdam, The Netherlands, February 20-22. doi: 10.2118/104609-MS.

[7] Halliburton, Landmark WELLPLAN [Software Program]. Available from Halliburton.

[8] Bourgoyne, A.T, K.K Millheim, M.E Chenevert, F.S Young. 1986. Applied Drilling Engineering. Richardson: Society of Petroleum Engineers.

[9] Sheppard, M.C, C. Wick, T. Burgess. 1987. "Designing Well Paths to Reduce Torque and Drag." SPE Drilling Engineering 2 (4): 344-350. doi: 10.2118/15463-PA.

[10] Aadnoy, B.S, J. Djurhuus. 2008. "Theory and Application of a New Generalized Model of Torque and Drag." Paper was prepared for presentation at 2008 IADC/SPE Asia Pacific Drilling Technology Conference, Jarkarta, Indonesia, August 25-27. doi: 10.2118/114684-MS.

[11] Aadnoy, B.S, M. Fazaelizadeh, G. Hareland. 2010. "A 3D Analytical Model for Wellbore Friction." Journal of Canadian Petroleum Technology 49 (10): 25-36. doi: 10.2118/141515-PA.

[12] Norwest Energy. 2011. Redhill South-1 Well Completion Report.

[13] Norwest Energy. 2011. Drilling and Evaluation Programme for Redhill South-01 Exploration Well.

[14] Maehs, J, S. Renne, B. Logan, N. Diaz. 2010. "Proven Methods and Techniques to Reduce Torque and Drag in the Pre-Planning and Drilling Execution of Oil and Gas Wells." Paper was prepared for presentation at 2010 IADC/SPE Drilling Conference and Exhibition, Louisiana, USA, February 2-4. doi: 10.2188/128329-MS. 